\title{
Developments in Understanding Diffuse Noxious Inhibitory Controls: Pharmacological Evidence from Pre-Clinical Research
}

\author{
Mateusz Wojciech \\ Kucharczyk (iD* \\ Diego Valiente (iD) \\ Kirsty Bannister (D) \\ Central Modulation of Pain Group, \\ Institute of Psychiatry, Psychology and \\ Neuroscience, King's College London, \\ London, SEI IUL., UK \\ *These authors contributed equally to \\ this work
}

\begin{abstract}
Bulbospinal pathways regulate nociceptive processing, and inhibitory modulation of nociception can be achieved via the activity of diffuse noxious inhibitory controls (DNIC), a unique descending pathway activated upon application of a conditioning stimulus (CS). Numerous studies have investigated the effects of varied pharmacological systems on the expression status of a) DNIC (as measured in anaesthetised animals) and b) the descending control of nociception (DCN), a surrogate measure of DNIC-like effects in conscious animals. However, the complexity of the underlying circuitry that governs initiation of a top-down inhibitory response in reaction to a $\mathrm{CS}$, coupled with the methodological limitations associated with using pharmacological tools for its study, has often obscured the exact role(s) of a given drug. In this literature review, we discuss the pharmacological manipulation interrogation strategies that have hitherto been used to examine the functionality of DNIC and DCN. Discreet administration of a substance in the spinal cord or brain is considered in the context of action on one of four hypothetical systems that underlie the functionality of DNIC/DCN, where interpreting the outcome is often complicated by overlapping qualities. Systemic pharmacological modulation of DNIC/DCN is also discussed despite the fact that the precise location of drug action(s) cannot be pinpointed. Chiefly, modulation of the noradrenergic, serotonergic and opioidergic transmission systems impacts DNIC/DCN in a manner that relates to drug class, route of administration and health/disease state implicated. The advent of increasingly sophisticated interrogation tools will expedite our full understanding of the circuitries that modulate naturally occurring pain-inhibiting pathways.
\end{abstract}

Keywords: endogenous pain modulation, descending pain control, diffuse noxious inhibitory controls, descending control of nociception, conditioned pain modulation, monoamines

\section{Introduction}

DNIC expression, quantified in unconscious animals as the inhibitory effect of a conditioning stimulus (CS) on spinal or trigeminal wide dynamic range (WDR) neuron activity, requires the application of two remote, noxious stimuli. Classically, the first stimulus applied is called the test stimulus (TS), while the second represents the CS (which may be applied subsequently, or concurrently, to the TS). The purpose of this review is to present knowledge regarding the distinct pharmacological systems that sub-serve functional DNIC expression. The study selection details are based on PubMed database search as of 11th January 2021 for:
Correspondence: Kirsty Bannister Wolfson Centre for Age-Related

Diseases, Guy's Campus, King's College

London, London, SEI IUL, UK

Tel +44 2078484617

Fax +442078486806

Email kirsty.bannister@kcl.ac.uk 
"(((diffuse noxious inhibitory controls) OR diffuse noxious inhibitory control) NOT humans [MeSH Terms]) NOT review" (See Scheme 1).

The purported measurement of the impact of pharmacological manipulation on the functionality of a "DNIC-like" pathway in conscious behaving animals (where pain-like behaviours are modulated upon application of a CS) is also discussed, where descending control of nociception (DCN) terminology is applied as recently advised. ${ }^{1}$

\section{Mechanistic Underpinnings}

The mechanism underlying the observed inhibition of spinal wide dynamic range neurons to a TS upon application of a CS involves, in part, neurotransmitter release from a yet undefined brainstem nucleus and its ensuing descending projection. Here we name this the descending effector system. This descending effector system acts via a so-called executive system to inhibit spinal nociception. Therefore, the top-down modulatory system consists of the internal brain circuits modulating the descending brainstem neuron of the effector system while the bottom-up modulatory system consists of two ascending branches (activated upon application of the TS and CS) (Figure 1).
Following this logic, local application of a pharmacological agent in the executive system has the limitation of affecting not only the executive system but also the transmission of the ascending TS branch and the terminals of the descending effector system. This complicates the interpretation of the results obtained, where assigning drug action to one discreet target is not possible. An added layer of complexity occurs when considering the pharmacological action of an agent in a rodent model of chronic pain, where the dominant pharmacological target ie, receptor subtype activated by a given agent may change according to the disease. ${ }^{2,3}$ To simplify this interpretation, we have conducted a thorough review of pharmacological DNIC studies with respect to the drug class, route of administration, readout method, and health/disease state implicated.

\section{Experimental Drug Targeting and Subsequent Impact on DNIC Expression}

Our analysis revealed that of 122 original DNIC and/or DCN research manuscripts, 42 studies investigated the impact of manipulation of a pharmacological system on DNIC expression status (Scheme 1). Of the 42 drugs tested, 14 acted on

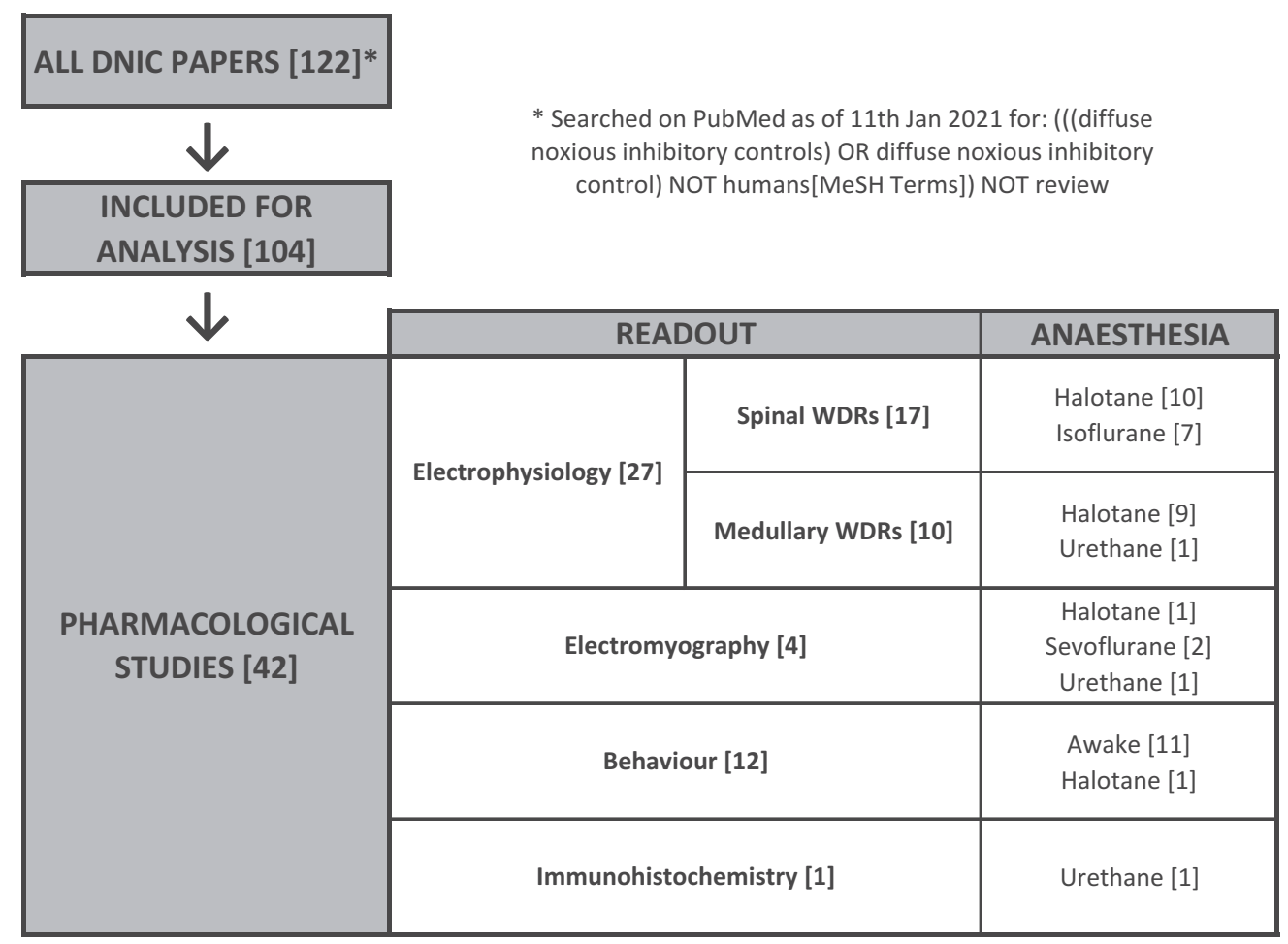

Scheme I Selected papers for analysis in this review. From I22 DNIC papers, 42 studies focused on the impact of pharmacological interventions on DNIC and/or DCN expression.

Abbreviations: WDR, wide dynamic range neurons; DNIC, diffuse noxious inhibitory controls; DCN, descending control of nociception. 


\section{Diffuse Noxious Inhibitory Controls (DNIC)}

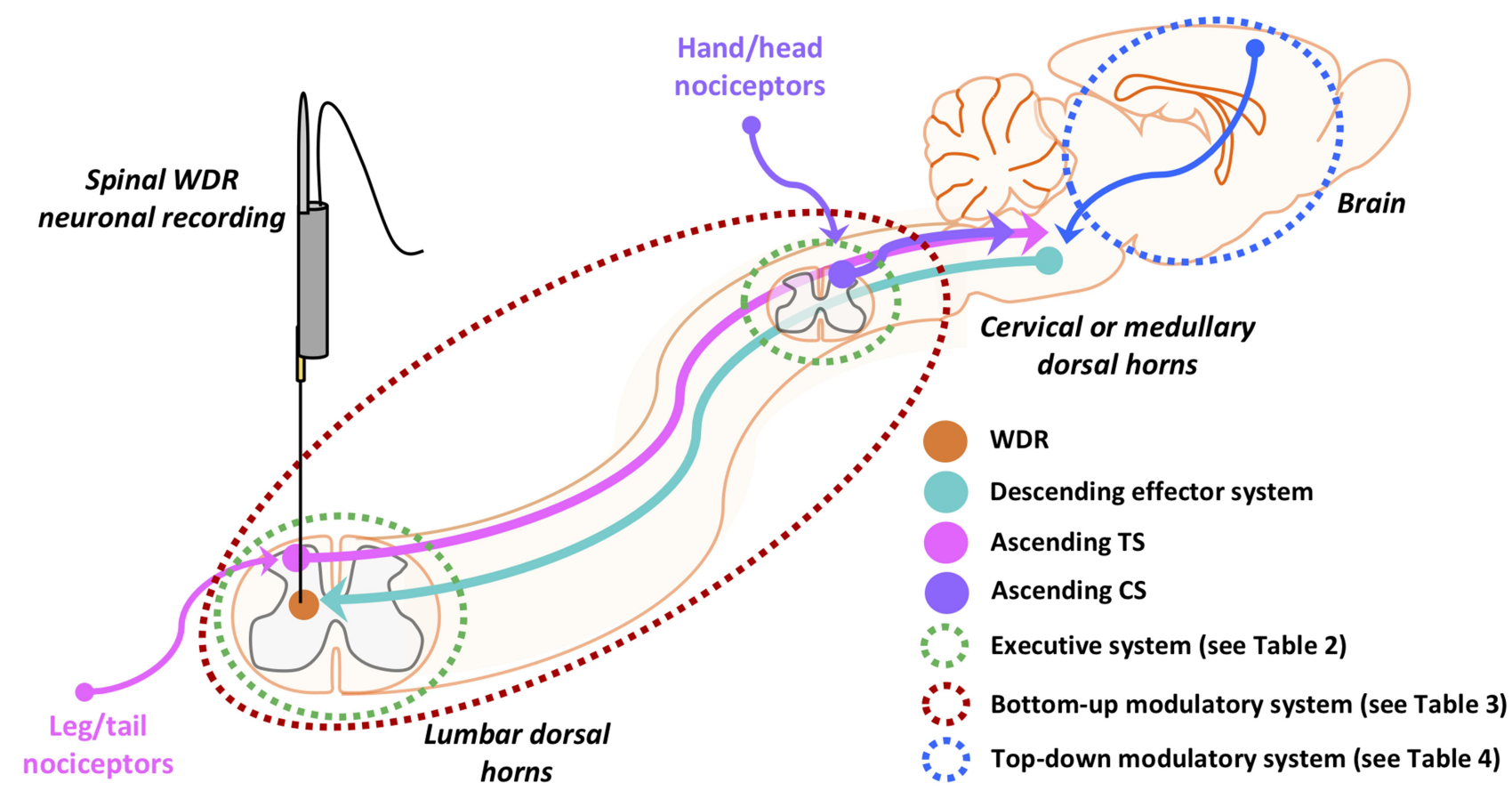

Figure I Schematic representation of the hypothetical systems involved in functional DNIC circuitry. The bottom-up modulatory system consists of input from two noxious stimuli: the testing stimulus (TS) and the conditioning stimulus (CS). The definition of the TS and CS is interchangeable, although traditionally the noxious stimulus first applied is referred to as the TS. To trigger DNIC, both the TS and CS must be presented to remote body regions. Recordings are made from wide dynamic range (WDR) neurons in spinal or medullary dorsal horns. Upon activation of nociceptors by the TS and CS, the descending effector system is activated. The effector system acts locally via receptors comprising the executive system to inhibit spinal nociceptive processing. Further complexity is introduced when considering that the spino (TS/CS)-bulbo (brainstem)-spinal (TS/CS) DNIC loop is additionally modulated by higher brain centres comprising the top-down modulatory system.

the serotoninergic system, 11 on the noradrenergic system, 9 on the opioidergic system, and 10 on other systems (Table 1). The most recurrent were studies of systemically administered morphine ( $\mu$ - and $\delta$-opioid receptor (MOR and DOR, respectively) agonist) (9 studies), followed by investigation of the systemic actions of naloxone (a non-selective opioid receptors antagonist) (7 studies), and investigation of citalopram, escitalopram, duloxetine or fluoxetine (selective serotonin reuptake inhibitors (SSRI)) (4 studies).

DNIC and/or DCN pharmacology was also investigated in the context of disease, where the most common diseases studied were nerve injury models of peripheral neuropathy, osteoarthritis and brain injury. The readout methods utilised reflect the separate DNIC/DCN mechanism studied (27 single unit electrophysiological studies and 12 behavioural studies, respectively) (Scheme 1). A complete table of reviewed literature can be found in the supplementary table (Supplementary Table 1).

\section{Pharmacological Manipulation of the Descending Effector System}

Several lines of evidence suggest a supraspinal, brainstem origin of DNIC and methodologies including lidocaine block of conduction at the level of cervical spinal cord, ${ }^{4}$ as well as cervical cord transection, ${ }^{4,5}$ have initiated the search for the origin nucleus of DNICs. Lesions to the dorsolateral funiculus (DLF) evidenced that DNIC descending fibres travel via a pathway ipsilateral to the WDR neuron being recorded. ${ }^{6,7}$ A set of brainstem transection experiments narrowed the area for DLF somas involved in DNIC to a joint between the medulla and pons. ${ }^{8}$ While a search for the exact origin nucleus is ongoing, several pharmacological studies have shed light on the potential neurotransmitter(s) involved in subserving the functionality of DNICs.

Two studies utilised selective inhibitors or neurotoxins that target monoaminergic neurons both spinally and 
Table I List of Drugs Tested to Influence DNIC Expression

\begin{tabular}{|c|c|c|c|c|c|}
\hline Drug & Pharmacology & 5HT & NA & Opioid & Other \\
\hline 5,7-dihydroxytryptamine & Neurotoxin depleting serotonergic fibers & & & & \\
\hline p-chlorophenylalanine & $\begin{array}{l}\text { Irreversible inhibitor of tryptophan hydroxylase (serotonin } \\
\text { depletion) }\end{array}$ & & & & \\
\hline 5-hydroxytryptophan & Serotonin precursor & & & & \\
\hline Sumatriptan succinate & 5-HT, receptor agonist & & & & \\
\hline WAY-100635 & $5-\mathrm{HT}_{\mathrm{IA}}$ receptor antagonist & & & & \\
\hline Metergoline & $5-\mathrm{HT}_{1}, 5-\mathrm{HT}_{2}$ and $5-\mathrm{HT}_{7}$ receptor antagonist & & & & \\
\hline Cinanserin & $5-\mathrm{HT}_{2 \mathrm{~A}}$ and $5-\mathrm{HT}_{2 \mathrm{C}}$ receptor antagonist & & & & \\
\hline Ondansetron & $5-\mathrm{HT}_{3}$ receptor antagonist & & & & \\
\hline AS-19 & $5-\mathrm{HT}_{7}$ receptor agonist & & & & \\
\hline SB269970 & $5-\mathrm{HT}_{7}$ receptor antagonist & & & & \\
\hline Citalopram & SSRI & & & & \\
\hline $\begin{array}{l}\text { Escitalopram } \\
\text { hydrochloride }\end{array}$ & SSRI & & & & \\
\hline Fluoxetine & SSRI & & & & \\
\hline Duloxetine & SNRI & & & & \\
\hline $\begin{array}{l}\text { Dopamine beta- } \\
\text { hydroxylase saporin } \\
\text { complex }\end{array}$ & Neurotoxin ablating noradrenergic neurons & & & & \\
\hline Phentolamine mesylate & $\alpha_{1 / 2}$-adrenoceptor antagonist & & & & \\
\hline Phenylephrine & $\alpha_{1}$-adrenoceptor agonist & & & & \\
\hline Yohimbine & $\alpha_{2}$-adrenoceptor antagonist & & & & \\
\hline Atipamezole & $\alpha_{2}$-adrenoceptor antagonist & & & & \\
\hline $\begin{array}{l}\text { Dexmedetomidine } \\
\text { hydrochloride }\end{array}$ & $\alpha_{2}$-adrenoceptor agonist & & & & \\
\hline Propranolol & Non-selective $\beta$-adrenoceptor antagonist & & & & \\
\hline Reboxetine mesylate & NRI & & & & \\
\hline $\begin{array}{l}\text { Desipramine } \\
\text { hydrochloride }\end{array}$ & NRI/TCA & & & & \\
\hline Tapentadol & $\mathrm{NRI}$ and MOR agonist & & & & \\
\hline $\begin{array}{l}\text { Buprenorphine } \\
\text { hydrochloride }\end{array}$ & Partial MOR agonist & & & & \\
\hline Morphine & MOR agonist & & & & \\
\hline DAMGO & MOR-DOR agonist & & & & \\
\hline Deltorphin II & DOR agonist & & & & \\
\hline
\end{tabular}

(Continued) 
Table I (Continued).

\begin{tabular}{|c|c|c|c|c|c|}
\hline Drug & Pharmacology & 5HT & NA & Opioid & Other \\
\hline Naloxone & Opioid receptor antagonist & & & & \\
\hline Naltrindole & DOR antagonist & & & & \\
\hline Nor-binaltorphimine & KOR antagonist & & & & \\
\hline ES 52 & Inhibitor of enkephalinase (derivative of Thiorphan) & & & & \\
\hline Sulpiride & Dopamine receptor 2 antagonist & & & & \\
\hline Isoflurane & General anaesthetic & & & & \\
\hline Kynurenate & Excitatory amino acid receptors antagonist & & & & \\
\hline Lidocaine & Voltage-gated sodium channels blocker & & & & \\
\hline Muscimol & Neurotoxin, GABA-A agonist & & & & \\
\hline Capsaicin & TRPVI agonist & & & & \\
\hline Celecoxib & COX-2 inhibitor & & & & \\
\hline Pregabalin & $\begin{array}{l}\text { Blocker of } \alpha 2 \delta I \text { of voltage-gated calcium channels (VGCCs) } \\
\text { trafficking to cell membrane (indirectly inhibits } \\
\text { neurotransmitter release) }\end{array}$ & & & & \\
\hline RP67580 & NKIR antagonist & & & & \\
\hline RP6758I & NKIR inactive antagonist & & & & \\
\hline
\end{tabular}

Notes: There were 42 drugs tested to influence DNIC expression. 14 acting on serotoninergic system. II acting on noradrenergic system. 9 acting on opioidergic system. 10 acting on other systems.

Abbreviations: TCA, tricyclic antidepressant; SSRI, selective serotonin reuptake inhibitor; NRI, selective noradrenaline reuptake inhibitor; SNRI, selective serotoninnoradrenaline reuptake inhibitor; MOR, $\mu$-opioid receptor; KOR, $\kappa$-opioid receptor; DOR, $\delta$-opioid receptor; COX2, cyclooxygenase 2.

supraspinally. In the first study, Dickenson et al delivered systemic p-chlorophenylalanine (p-CPA), an irreversible inhibitor of tryptophan hydroxylase that depletes wholebrain serotonin levels, and subsequently quantified DNIC expression by means of single unit electrophysiological WDR neuronal recordings in the lumbar spinal cord. The authors concluded an implied partial involvement of serotonergic pathways in DNIC functionality, "partial" because up to $35 \%$ of WDR neuronal inhibition upon application of the CS remained. ${ }^{9}$ In a second study, 5,7-dihydroxytryptamine (5,7-DHT), a neurotoxin that depletes descending serotonergic fibres, was injected intrathecally and DCN expression was assessed. Behaviourally assessed DCN expression was intact suggesting that descending serotonin is not a direct mediator of DCN at the effector site. ${ }^{10}$ However, interestingly the same study reported that intracerebroventricular injection of dopamine $\beta$-hydroxylase saporin conjugate (D $\beta \mathrm{H}$-Sap), a neurotoxin that ablates noradrenergic neurons, abolished DCN expression.
No ablation studies targeting dopaminergic fibres and subsequent impact on DNIC and/or DCN expression have been published to date. However, based on publicly available RNAseq datasets, the expression of receptors for dopamine in the spinal cord is scarce, therefore the execution of functional DNIC by descending dopaminergic pathways that sub-serve transmission in the spinal cord itself, lacks support. ${ }^{11}$

\section{Pharmacological Manipulation of the Executive System}

The concept of DNIC as depicted in Figure 1 proposes a local spinal (and trigeminal) release of neurotransmitter(s) from descending fibres upon application of a CS. Released mediator would be presumed to manifest its action via the relevant receptor expressed in the spinal (or medullary) dorsal horns to ultimately inhibit nociception. Since the exact origin nucleus of the DNIC projection remains under investigation, exact receptor(s) of the executive system remain elusive also. 
The general ablation studies (see section A) suggest that noradrenaline is a major neurotransmitter involved in the mediation of DCN via the effector system. This couples well with the local spinal action of selective $\alpha_{2}$-adrenergic receptors $\left(\alpha_{2}-\mathrm{AR}\right)$ antagonist atipamezole in abolishing DNIC expression in healthy anaesthetised animals. ${ }^{12}$ Atipamezole was also shown to abolish DNIC expression in the early stage of monoiodoacetate (MIA) model of osteoarthritis (OA). ${ }^{13}$ Furthermore, intrathecal application of another $\alpha_{2}$-AR antagonist yohimbine, also potently abolished DCN expression in three independent behavioural studies ${ }^{14-16}$ (Table 2).

The literature suggests that two separate descending monoaminergic systems interact in the executive system, where the balance in transmission that ensues is crucial for functional DNIC expression. An imbalance of facilitatory serotoninergic and inhibitory noradrenergic controls may be the reason why, in some pathological states including peripheral neuropathy, DNIC expression is abolished. ${ }^{3,12,13}$ The dysfunctional DNIC phenotype can be rescued upon spinal application of both noradrenaline reuptake inhibitors $(\mathrm{NRI})^{12}$ and selective serotonin reuptake inhibitors (SSRI), ${ }^{3}$ highlighting the complexity of monoamine modulators in the overall DNIC response. Mechanistically, an ability of the SSRIs to reveal functional DNIC in spinal nerve ligated rats was linked to spinal $5-\mathrm{HT}_{7}$ and $5-\mathrm{HT}_{1 \mathrm{a}}$ receptors (Table 2), ${ }^{13,15}$ while a separate study suggested that dopamine receptor 2 is involved in DNIC expression in the trigeminal system. ${ }^{17}$ Interestingly, despite the fact that many studies have focused on the role of the opioidergic system in DNIC functionality, a role for opioids in the DNIC executive system has not been directly tested, nor has the involvement of other systems including those utilising GABA and glutamate transmission. Whether other neurotransmitters such as GABA or enkephalin are directly involved in DNICs' executive system remains unknown. However, despite the fact that GABAergic long-range (bulbospinal) fibres exist, their inhibitory actions tend to be modality specific and DNIC actions are polymodal. ${ }^{18}$

\section{Pharmacological Manipulation of the Bottom-Up Modulatory System (Ascending TS and CS)}

Local spinal receptors and peripheral nociceptors are documented as being involved in the transmission of test and/or conditioning stimulus noxious impulses, meaning that they too can affect DNIC. Unsurprisingly, a peripheral block to the nerve conducting either the TS or CS has been shown to negatively impact DNIC expression. ${ }^{19}$ Opioid receptors were shown to be involved in the ascending signalling aspect of DNIC since both selective MOR agonist (DAMGO) and DOR agonist (Deltorphin II) abolished DNIC expression when applied intrathecally in the region specific to the CS input. ${ }^{20}$

Identification of the precise transmission system(s) involved whereupon DNIC is triggered and/or executed remains equivocal. However, recently a strong recommendation was put forward regarding the involvement of spinal lamina I projection neurons expressing neurokinin receptor 1 (NK1R). The spinal NK1R neurons constitute a major nociceptive transmission system in rodents, projecting chiefly from the superficial dorsal horns to the pontine lateral parabrachial area (lPB). ${ }^{21,22}$ An elegant study by Lapirot et al demonstrated that a local antagonism of spinal NK1R by a compound called RP67580 abolished DCN in behaving rats. The authors also showed that inhibition of the IPB area with a $\mathrm{GABA}_{\mathrm{A}}$ agonist muscimol, reduced DNIC-evoked inhibition in recorded medullary WDR neurons. ${ }^{23}$ Since DNIC were not completely abolished in this study, the involvement of other ascending circuits remains to be elucidated (Table 3).

Given the complexity of the DNIC circuitry, the results discussed could be also viewed from a different angle, whereby the local application of an agent in the CS or TS input area would also act on the executive system. In short, separation of ascending CS/TS and executive descending system(s) cannot be precisely addressed with pharmacological tools such as those described. Rather, selective neuron-type-specific receptor knockout studies and activation/inhibition of discreet, genetically-defined, neuronal populations with novel tools such as chemo- or optogenetics is required to answer this question.

\section{Pharmacological Manipulation of the Top-Down Modulatory System}

The spino (TS/CS)-bulbo(brainstem)-spinal (TS/CS) DNIC loop is also modulated by higher brain centres comprising the top-down modulatory system. We have subdivided the top-down modulatory systems into those originating from the medullary nuclei and those from higher brain centres (located rostrally to the brainstem) (Table 4). The former could be also considered as part of the bottom-up circuits, however their exact role(s) requires further study. 


\begin{tabular}{|c|c|c|c|c|c|c|c|c|c|c|c|c|c|c|c|c|c|c|c|c|}
\hline 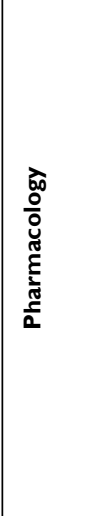 & 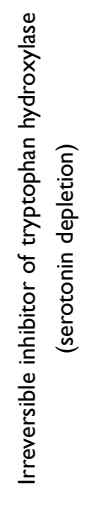 & 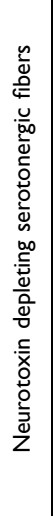 & 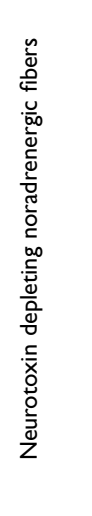 & 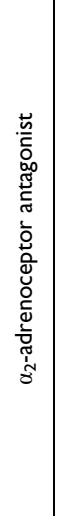 & 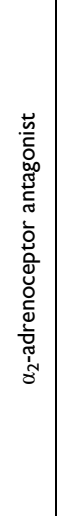 & 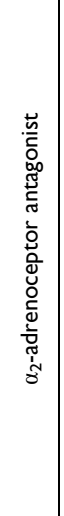 & 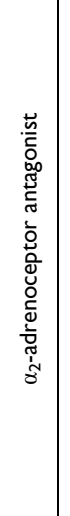 & 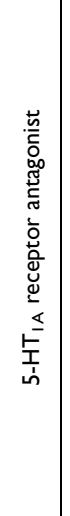 & 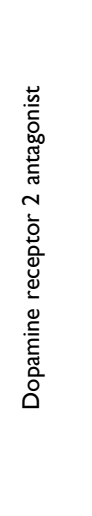 & 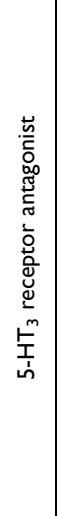 & $\overline{\underline{z}}$ & 岕 & 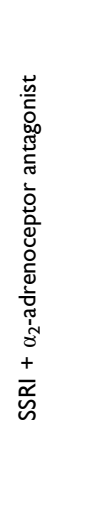 & 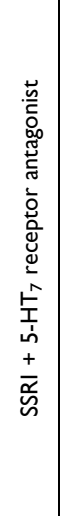 & 总 & 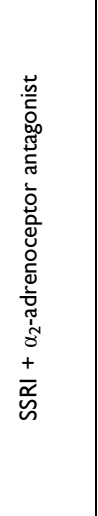 & 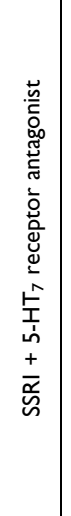 & 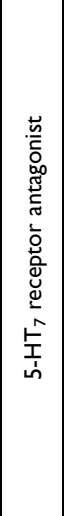 & 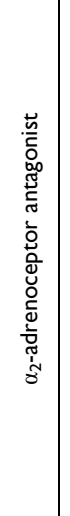 & 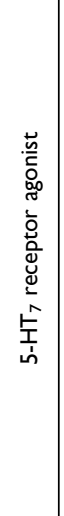 \\
\hline 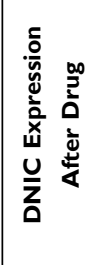 & 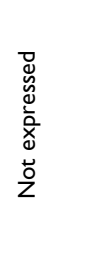 & 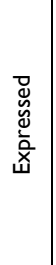 & 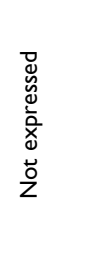 & 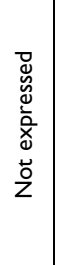 & 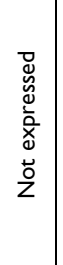 & 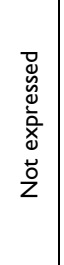 & 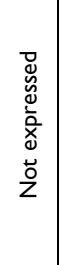 & 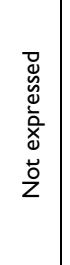 & 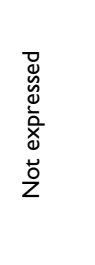 & 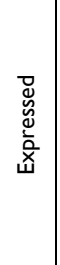 & 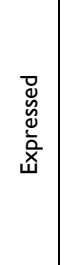 & 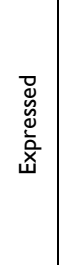 & 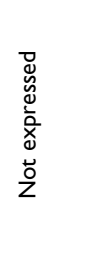 & 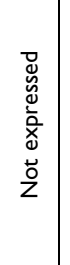 & 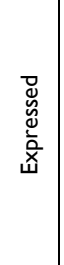 & 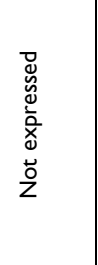 & 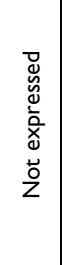 & 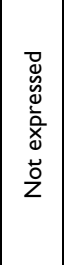 & 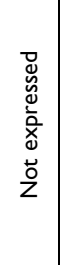 & 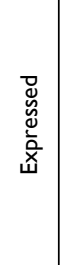 \\
\hline 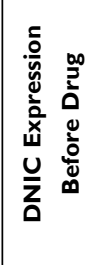 & 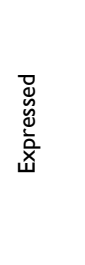 & 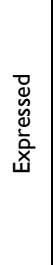 & 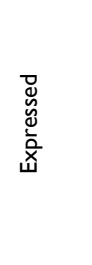 & 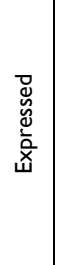 & 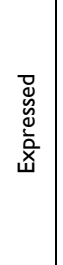 & 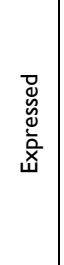 & 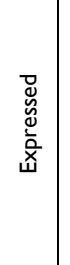 & 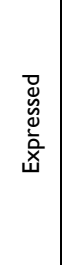 & 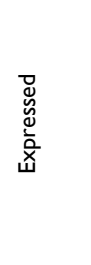 & 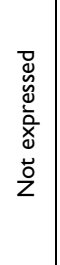 & 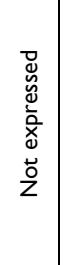 & 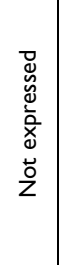 & 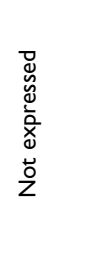 & 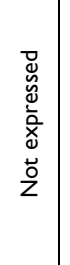 & 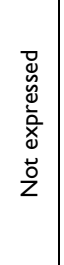 & 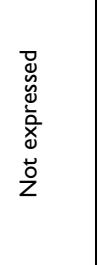 & 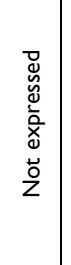 & 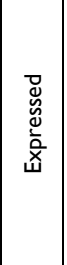 & 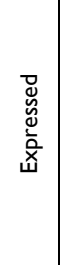 & 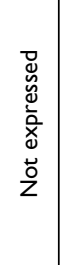 \\
\hline 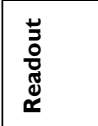 & 듭 & $\stackrel{-}{\bar{๊}}$ & $\stackrel{\complement}{\bar{\Phi}}$ & $\frac{\ulcorner}{\Phi}$ & $\stackrel{\ulcorner}{\Phi}$ & $\stackrel{\ulcorner}{\bar{\Phi}}$ & 현 & $\stackrel{\ulcorner}{\Phi}$ & 현 & 点 & 后 & 总 & 立 & $\frac{c}{\omega}$ & $\frac{c}{\omega}$ & 현 & 듭 & 협 & 扂 & 홉 \\
\hline 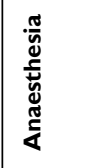 & 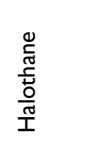 & $\widehat{s}$ & $\widehat{\Sigma}$ & 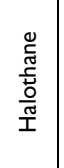 & 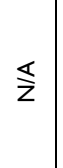 & 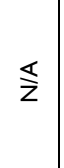 & 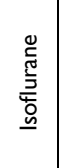 & $\underline{\Sigma}$ & 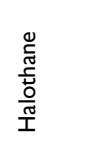 & 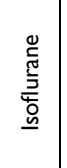 & 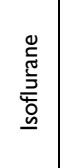 & 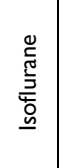 & 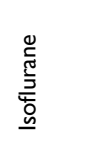 & $\begin{array}{l}\stackrel{0}{\tilde{g}} \\
\stackrel{\tilde{y}}{\overline{0}} \\
\underline{0}\end{array}$ & 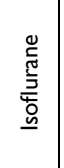 & 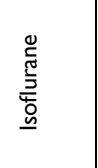 & 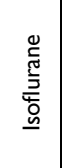 & 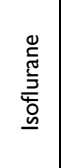 & 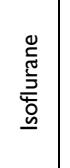 & 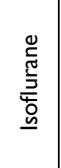 \\
\hline 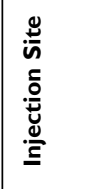 & $\stackrel{\leftrightarrow}{g}$ & 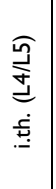 & نِنِ & 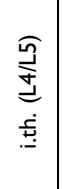 & 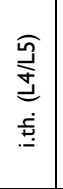 & 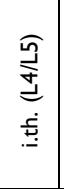 & 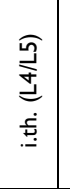 & 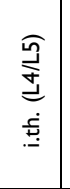 & 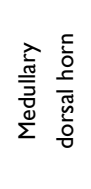 & 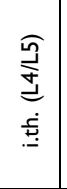 & 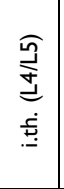 & 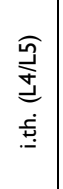 & 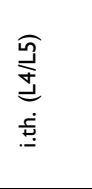 & 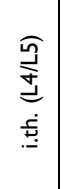 & 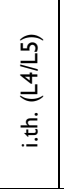 & 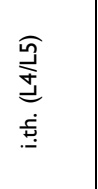 & 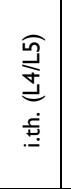 & 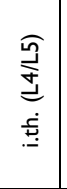 & 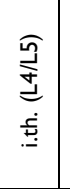 & 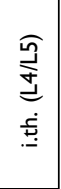 \\
\hline 岕 & 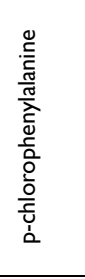 & 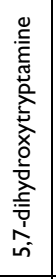 & 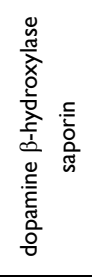 & 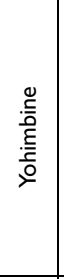 & 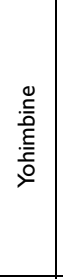 & 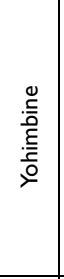 & 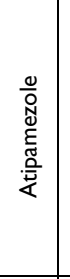 & 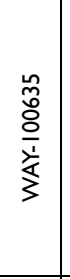 & 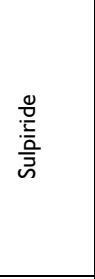 & 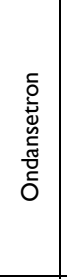 & 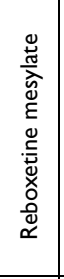 & 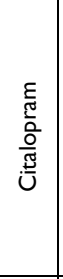 & 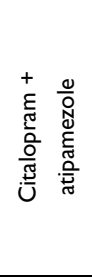 & 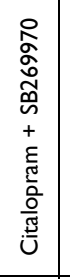 & 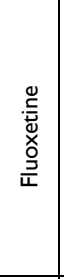 & 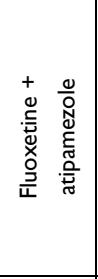 & 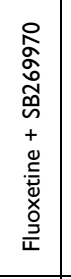 & 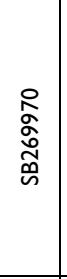 & 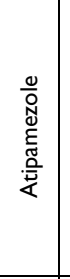 & $\frac{\sigma}{\dot{s}}$ \\
\hline 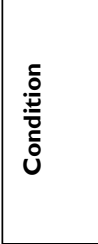 & : & : & 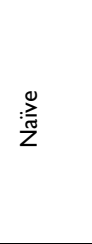 & $\sum_{\text {Zn }}^{0}$ & 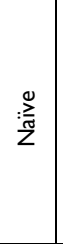 & $: \stackrel{0}{\text { : }}$ & 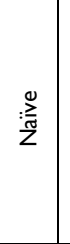 & $\sum_{\bar{N}}^{\frac{0}{Z}}$ & 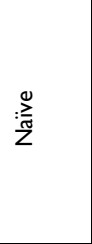 & $\vec{z}$ & $\vec{z}$ & $\vec{z}$ & $\vec{z}$ & $\vec{z}$ & $\vec{z}$ & $\vec{z}$ & $\vec{n}$ & 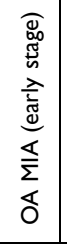 & 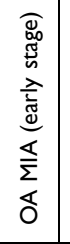 & 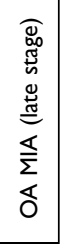 \\
\hline$\frac{\rho}{\Sigma}$ & 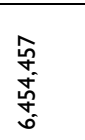 & 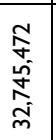 & 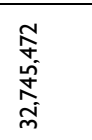 & 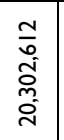 & 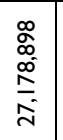 & $\begin{array}{l}\bar{i} \\
\frac{\hat{\omega}}{m} \\
\vec{j}\end{array}$ & 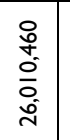 & $\begin{array}{l}\infty \\
0 \\
\infty \\
\infty \\
\stackrel{\infty}{\Lambda} \\
\stackrel{\sim}{N}\end{array}$ & 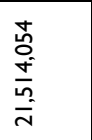 & 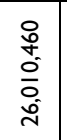 & 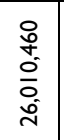 & 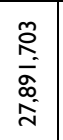 & 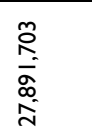 & 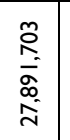 & 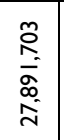 & 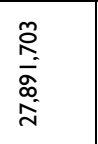 & 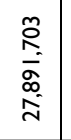 & 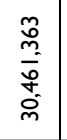 & 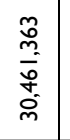 & $\begin{array}{l}m \\
\stackrel{0}{m} \\
\frac{0}{0} \\
0 \\
0 \\
0 \\
0\end{array}$ \\
\hline
\end{tabular}


Table 3 Pharmacological Manipulation of the Bottom-Up Modulatory System (Ascending TS and CS). Listed by the Drug

\begin{tabular}{|c|c|c|c|c|c|c|c|c|}
\hline PMID & Condition & Drug & Injection Site & Anaesthesia & Readout & $\begin{array}{c}\text { DNIC } \\
\text { Expression } \\
\text { Before Drug }\end{array}$ & $\begin{array}{c}\text { DNIC } \\
\text { Expression } \\
\text { After Drug }\end{array}$ & Pharmacology \\
\hline $3,763,236$ & Naïve & $\begin{array}{l}\text { Morphine } \\
\text { sulfate }\end{array}$ & i.th. (Sacral) & Halothane & Eph & Expressed & $\begin{array}{l}\text { Expressed } \\
\quad \text { (paw) } \\
\text { Not } \\
\text { expressed } \\
\text { (tail) }\end{array}$ & $\begin{array}{l}\text { MOR-DOR } \\
\text { agonist }\end{array}$ \\
\hline$|9,23|, 08 \mid$ & Naïve & RP6758I & i.th. (L4/L5) & N/A & Beh & Expressed & Expressed & $\begin{array}{c}\text { NKIR inactive } \\
\text { antagonist }\end{array}$ \\
\hline$|9,23|, 08 \mid$ & Naïve & RP67580 & i.th. (L4/L5) & N/A & Beh & Expressed & $\begin{array}{c}\text { Not } \\
\text { expressed }\end{array}$ & $\begin{array}{c}\text { NKIR } \\
\text { antagonist }\end{array}$ \\
\hline$|9,23|, 08 \mid$ & Naïve & Muscimol & $\begin{array}{c}\text { Lateral } \\
\text { parabrachial area } \\
\text { (IPB) }\end{array}$ & Halothane & Eph & Expressed & $\begin{array}{l}\text { Not } \\
\text { expressed }\end{array}$ & $\begin{array}{c}\text { Neurotoxin, } \\
\text { GABA-A } \\
\text { agonist }\end{array}$ \\
\hline $23,843,537$ & Naïve & $\begin{array}{l}\text { DAMGO- } \\
\text { enkephalin }\end{array}$ & i.th. (L4/L5) & Halothane & Eph & Expressed & $\begin{array}{c}\text { Not } \\
\text { expressed }\end{array}$ & MOR agonist \\
\hline $23,843,537$ & Naïve & $\begin{array}{c}\text { Deltorphin } \\
\text { II }\end{array}$ & i.th. (L4/L5) & Halothane & Eph & Expressed & $\begin{array}{c}\text { Not } \\
\text { expressed }\end{array}$ & DOR agonist \\
\hline $8,973,815$ & Naïve & Capsaicin & $\begin{array}{l}\text { Directly on the } \\
\text { sciatic nerve } \\
\text { (cotton ball) }\end{array}$ & $\begin{array}{l}\text { Thiamylal } \\
\text { sodium }\end{array}$ & EMG & Expressed & $\begin{array}{c}\text { Not } \\
\text { expressed }\end{array}$ & TRPVI agonist \\
\hline
\end{tabular}

Abbreviations: SNL, spinal nerve ligation model; OA MIA, monoiodoacetate model of osteoarthritis; i.p, intraperitoneal; i.th, intrathecal (L4/L5 - lumbar 4/5); Beh, behaviour; Eph, in vivo electrophysiology; EMG, electromyography; MOR, $\mu$-opioid receptor; DOR, $\delta$-opioid receptor.

Regarding higher brain centres, Patel and Dickenson previously reported that lidocaine inhibition of the infralimbic (ILC) region of the medial prefrontal cortex abolishes DNIC expression in healthy rats, while restoring DNIC expression in SNL animals. ${ }^{24}$ Focusing on the mesencephalon, morphine injected in the medioventral periaqueductal grey (MV-PAG) abolished DNIC expression in healthy animals. ${ }^{25}$ Previously, Phelps et al demonstrated that microinjection of norbinaltorphimine (nor-BNI), a א-opioid receptor (KOR) antagonist, into the right central nucleus of amygdala ( $\mathrm{RCeA}$ ) restored DCN and DNIC expression in neuropathic animals. ${ }^{26}$ Similar results were obtained in a morphine-primed environmental bright light stress model (MP-BLS) ${ }^{27}$ Cumulatively, the results propose an opioid sensitive top down modulation of DNIC and DCN circuitry from the RCeA. Interestingly, another paper reported that a MOR/DOR agonist morphine microinjected to the $\mathrm{RCeA}$ restored $\mathrm{DCN}$ in neuropathic rats. ${ }^{28}$ The data suggest an opposite role of MOR/DOR and KOR receptors within the RCeA in terms of their control of DNIC/DCN expression.

Turning to the brainstem, morphine microinjection in the nucleus raphe magnus (RMg) did not abolish DNIC expression in healthy rats. ${ }^{29}$ Interestingly, antagonism of KOR by nor-BNI in the rostral ventromedial medulla (RVM) did not restore DCN in MP-BLS animals, ${ }^{27}$ but naloxone (a non-selective opioid receptors antagonist) injected therein had no effect on DCN expression in rats with muscle inflammation. ${ }^{30}$ Caudal parts of the medulla seem to have different sensitivity to opioids. For instance, naloxone dosed in the medullary reticularis dorsalis nucleus (MdD) abolished DCN in rats with muscle inflammation, ${ }^{30}$ and so did its injection in the dorsal reticular nucleus (DRt). ${ }^{24}$ Intriguingly, in neuropathic animals lacking DNIC expression, microinjection of naloxone to the DRt restored DNIC. ${ }^{24}$

These studies advocate for the complexity of interactions for pharmacological systems in terms of the functionality of DNIC pathways.

\section{Systemic Pharmacological Administration}

Systemic drug administration is of the upmost importance when considering the potential translation of animal studies 


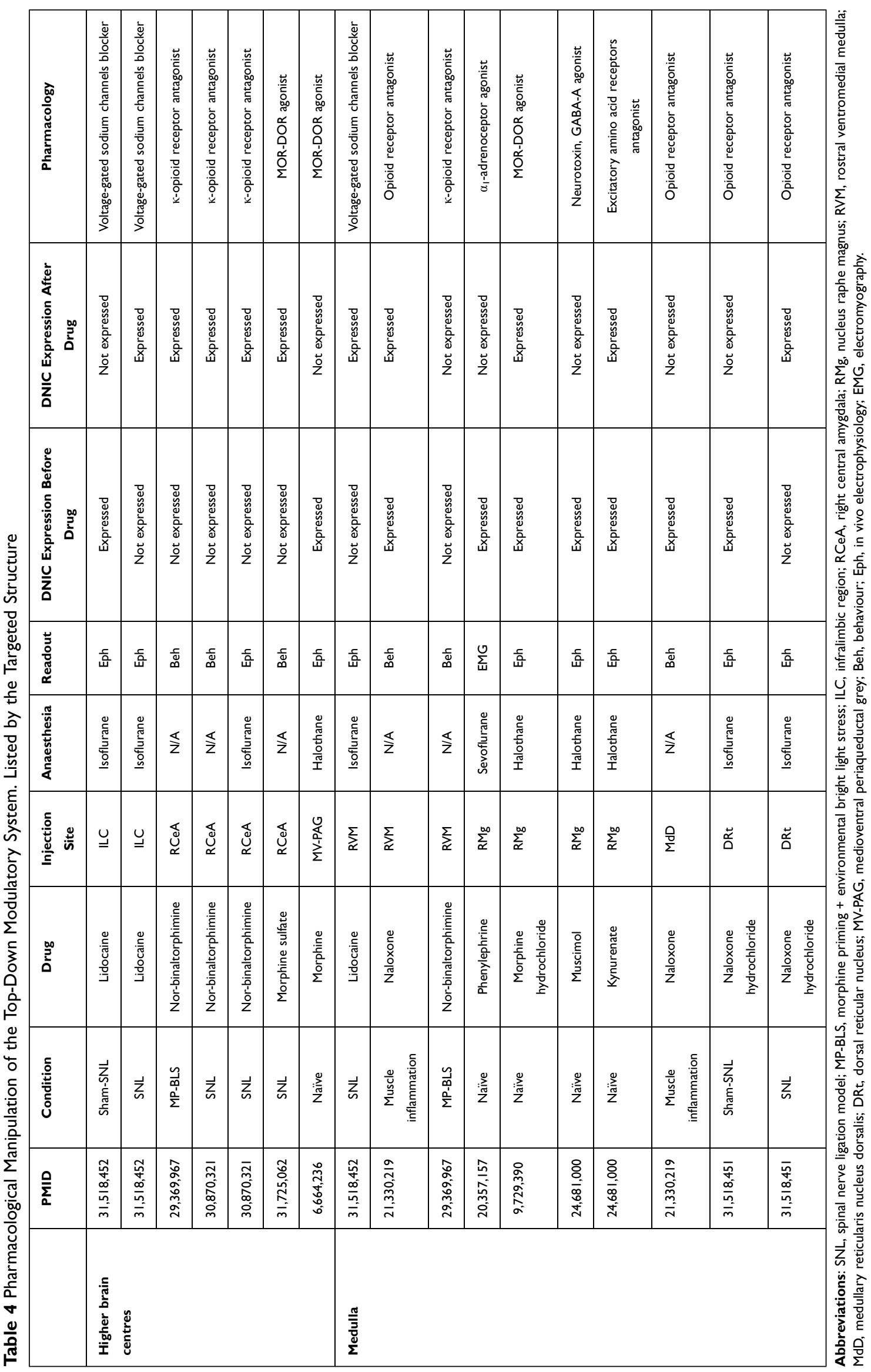


to the general clinical picture, however the functional information gained is impeded by the fact that it is not possible to pinpoint the precise location of actions observed.

Nonetheless in principal, mechanistic insight can be gained when using systemic drug administration. An informative approach, however, comes from recapitulating the systemic effect(s) of a drug by its microinjection to a discreet part of the body in order to infer its main target(s). In several instances the local action of a drug could differ from its overall systemic picture. Interestingly, a seemingly opposite action of a given drug administered in a discreet location may contribute to the final systemic effect equally. For example, an inhibitory action of noradrenaline via $\alpha_{2}$-ARs located on inhibitory interneurons would result in a net facilitation by removing inhibitory tone from those interneurons. Therefore, the activation of a seemingly "inhibitory" receptor could result in net facilitation. What is more, the same agent may have different receptors affinities, confusing an overall response if the dosing is not careful and accurate location of drug action is not identified (ie noradrenaline has 6 times higher affinity to inhibitory $\alpha_{2}$-ARs than to excitatory $\alpha_{1}$-ARs).

Furthermore, considering the main pharmacokinetic components (liberation, absorption, distribution, metabolism, and excretion (LADME)), it is especially important to test many doses of a drug delivered systemically. An opposite action may be apparent when a drug reaches sufficient concentrations at only the peripheral vs CNS targets. Therefore, systemic studies should involve a broad range of doses to confidently state the exact role of a given drug.

Frequently such studies have involved systemic morphine (9 studies) or naloxone (7 studies) (Supplementary Table 2). As presented earlier, the complexity of supraspinal actions of opioids can be informative regarding their overall mechanism of action when analysing the effects of their systemic administration. For instance, systemic administration of naloxone abolishes $\mathrm{DNIC}^{31,32}$ and $\mathrm{DCN}^{14,15,30,33}$ expression in naïve rats. This recapitulates the involvement of opioidergic mechanisms from the DRt or MdD where naloxone also abolished DNIC expression, ${ }^{24,30}$ but not those from the RVM, where DNIC were not affected by microinjected naloxone. ${ }^{30}$ However, it is still unclear if the systemic effect of naloxone is mediated by other cerebral, spinal (or possibly) joint mechanisms, as the drug is distributed throughout the body within minutes.

Agonism of MOR/DOR by systemic morphine consistently abolished $\mathrm{DNIC}^{34-39}$ and $\mathrm{DCN}^{27,40}$ expression. In some instances, morphine was also administered jointly with naloxone, either by intravenous or intracerebroventricular injection, and DNIC expression remained functional. ${ }^{34,35,38,39}$ In 2 additional studies systemically administered morphine did not abolish DNIC expression in PAG lesioned rats, ${ }^{35}$ nor DCN expression in rats receiving a continuous morphine delivery from osmotic minipumps. ${ }^{27}$ While the results of the former study suggest an involvement of the PAG in DNICs' sensitivity to morphine, the latter is inconclusive as another 2 studies also delivered morphine continuously and a diminished $\mathrm{DNIC}^{36}$ or $\mathrm{DCN}^{40}$ response resulted. Interestingly, systemic administration of KOR antagonist nor-BNI restored DCN in the spinal nerve ligation (SNL) model of peripheral neuropathy, and in the MP-BLS model, recapitulating those results observed upon RCeA administration. ${ }^{26,27}$ Similarly tapentadol, a joint noradrenaline reuptake inhibitor (NRI) and MOR agonist, given systemically restored DNIC in SNL rats and late stage OA models. ${ }^{12,13,41}$

Surprisingly, the systemic action of noradrenergic drugs has not been extensively studied. Systemic atipamezole, an $\alpha_{2}$-ARs antagonist, recapitulates the effects observed when administered locally on the spinal cord in terms of abolishing DCN expression in healthy animals. ${ }^{10}$ Strangely however similar effects were observed upon systemic administration of $\alpha_{2}$-ARs agonist dexmedetomidine and $\alpha_{1}$-ARs agonist phenylephrine. ${ }^{42}$

Regarding the serotoninergic system, systemic administration of metergoline, an antagonist of $5-\mathrm{HT}_{1}, 5-\mathrm{HT}_{2}$ and $5-\mathrm{HT}_{7}$ receptors, abolished DNIC expression in healthy rats. ${ }^{43}$ Contrasting, 5- $\mathrm{HT}_{2 \mathrm{~A}}$ and $5-\mathrm{HT}_{2 \mathrm{C}}$ receptor antagonist cinanserin has an inconclusive role; in one study it abolished DNIC expression, ${ }^{43}$ while in another its systemic administration did not affect DCN expression. ${ }^{44}$ This feeds into the current viewpoint regarding the differential mechanistic underpinnings of DNIC versus DCN. A reduction in pain-like behaviours upon application/administration of a conditioning stimulus evidently portrays execution of distinct top down modulatory processes compared to measurement of a functional DNIC response in anaesthetised animals. ${ }^{1}$ Explicitly, the subject's conscious state now encompasses cognitive inputs that will impact the response observed upon conditioning. That said the functional expression of DNIC was previously shown modulated by pharmacological manipulation of subcortical brain regions ${ }^{26}$ bolstering a hypothesised scenario whereby DCN may involve DNIC mechanisms, but not the other way round. Meanwhile, sumatriptan, a 5-HT 1 receptor agonist, abolished DCN expression in naïve animals suggestive of an important role for this 
serotonin receptor subtype (jointly with the result of metergoline). ${ }^{40}$

Systemic administration of monoamine reuptake inhibitors has also been extensively tested. In the SNL model of peripheral neuropathy citalopram and fluoxetine, both SSRIs, failed to restore DNIC, ${ }^{3}$ but escitalopram (also $\mathrm{SSRI}$ ) restored DCN in traumatic brain injury (TBI) model, however an effect of the latter was not abolished by systemically applied atipamezole. ${ }^{10}$ Duloxetine, an serotonin noradrenaline reuptake inhibitor (SNRI), restored DCN expression in late stage OA and PSNL models, ${ }^{16}$ as well as in a TBI model. ${ }^{10}$ Interestingly, systemic reboxetine, a NRI, did not restore DCN in TBI animals, ${ }^{10}$ but its local spinal application did restore DNIC in SNL animals. $^{12}$ Those SSRI, SNRI and NRI studies jointly suggest that, as for their systemic action, SNRIs are drugs of choice in terms of restoring dysfunctional DNIC expression. The fact that local spinal NRIs are sufficient to restore DNIC suggests that a serotoninergic component is likely involved in both the spinal and supraspinal mechanisms necessary for functional DNIC expression.

Finally, other agents like celecoxib, a cyclooxygenase type 2 (COX2) inhibitor, given orally, did not restore DCN in PSNL nor in late stage OA rats. ${ }^{16}$ Systemic pregabalin (an analgesic acting on voltage-gated calcium channels (VGCCs) inhibiting calcium currents and de facto the release of neurotransmitters) also failed to restore DNIC and DCN expression in the late stage OA model and in an injury model of peripheral neuropathy. ${ }^{16,41}$

Precisely, noradrenergic mechanisms are essential for the proper functioning of the DNIC pathway. A clear investigative focus on the reciprocal connectivity of brainstem noradrenergic nuclei with respect to their functionality upon conditioning is crucial to delineate the hierarchy of nucleus contributions to this unique type of inhibitory control. The effects of other modulators appear to depend on 1) local levels in the transmission system, where the observed effect itself changes according to receptor subtype(s) preferentially activated and/or 2) the circuitry modulated in the pain neuroaxis, where an immediate-future research focus on the precise forebrain modulation of the DNIC pathway is of high interest. In all instances, pharmacological modulatory mechanisms are impacted by disease state highlighting the importance of studying the DNIC/DCN circuitry in health as well as disease.

\section{Conclusions}

While many systems are involved in the final expression status of DNIC and/or DCN (where overlapping commonalities are under investigation), not all have been pharmacologically tested. Despite many studies, question marks remain regarding peripheral versus central mechanisms of action for the opioids as well as the modulatory role of serotonin, likely not to be a direct mediator of DNIC at least. This links to difficulties interpreting the spinal versus supra-spinal mechanisms of substance action, where the overlapping features of the circuitries involved in, for example, the descending effector and executive system, means that teasing apart functionality using pharmacology is difficult.

\section{Acknowledgments}

The authors would like to thank Professor Stephen B. McMahon (King's College London) for securing funding for DV.

\section{Author Contributions}

All authors contributed to data analysis, drafting or revising the article, have agreed on the journal to which the article will be submitted, gave final approval of the version to be published, and agree to be accountable for all aspects of the work.

\section{Funding}

$\mathrm{KB}$ and MWK are funded by a grant from the Academy of Medical Sciences (SBF004\1064) awarded to KB. DV receives funding from the European Union's Horizon 2020 research and innovation programme under the Marie Skłodowska-Curie grant agreement No 814244.

\section{Disclosure}

The authors have no conflicts of interest to declare.

\section{References}

1. Bannister K, Kucharczyk MW, Graven-Nielsen T, Porreca F. Introducing descending control of nociception: a measure of diffuse noxious inhibitory controls in conscious animals. Pain. 2021. doi:10.1097/j.pain.0000000000002203

2. Brenchat A, Nadal X, Romero L, et al. Pharmacological activation of 5-HT7 receptors reduces nerve injury-induced mechanical and thermal hypersensitivity. Pain. 2010;149(3):483-494. doi:10.1016/j. pain.2010.03.007

3. Bannister K, Lockwood S, Goncalves L, Patel R, Dickenson AH. An investigation into the inhibitory function of serotonin in diffuse noxious inhibitory controls in the neuropathic rat. Eur J Pain. 2017;21 (4):750-760. doi:10.1002/ejp.979

4. Cadden SW, Villanueva L, Chitour D, Le Bars D. Depression of activities of dorsal horn convergent neurones by propriospinal mechanisms triggered by noxious inputs; comparison with diffuse noxious inhibitory controls (DNIC). Brain Res. 1983;275(1):1-11. doi:10.1016/0006-8993(83)90412-2 
5. Morgan MM, Heinricher MM, Fields HL. Inhibition and facilitation of different nocifensor reflexes by spatially remote noxious stimuli. J Neurophysiol. 1994;72(3):1152-1160. doi:10.1152/jn.1994.72.3.1152

6. Villanueva L, Chitour D, Le Bars D. Involvement of the dorsolateral funiculus in the descending spinal projections responsible for diffuse noxious inhibitory controls in the rat. $J$ Neurophysiol. 1986;56 (4):1185-1195. doi:10.1152/jn.1986.56.4.1185

7. Calvino B. Is spinal cord dorsolateral funiculus involved in hypoalgesia induced by counter-irritation? Behav Brain Res. 1990;39 (2):97-111. doi:10.1016/0166-4328(90)90097-x

8. Bouhassira D, Chitour D, Villaneuva L, Le Bars D. The spinal transmission of nociceptive information: modulation by the caudal medulla. Neuroscience. 1995;69(3):931-938. doi:10.1016/03064522(95)00269-o

9. Dickenson AH, Rivot JP, Chaouch A, Besson JM, Le Bars D. Diffuse noxious inhibitory controls (DNIC) in the rat with or without pCPA pretreatment. Brain Res. 1981;216(2):313-321. doi:10.1016/00068993(81)90133-5

10. Irvine KA, Sahbaie P, Ferguson AR, Clark JD. Loss of diffuse noxious inhibitory control after traumatic brain injury in rats: a chronic issue. Exp Neurol. 2020;333:113428. doi:10.1016/j. expneurol.2020.113428

11. Häring M, Zeisel A, Hochgerner H, et al. Neuronal atlas of the dorsal horn defines its architecture and links sensory input to transcriptional cell types. Nat Neurosci. 2018;21(6):869-880. doi:10.1038/s41593018-0141-1

12. Bannister K, Patel R, Goncalves L, Townson L, Dickenson AH. Diffuse noxious inhibitory controls and nerve injury: restoring an imbalance between descending monoamine inhibitions and facilitations. Pain. 2015;156(9):1803-1811. doi:10.1097/j. pain.0000000000000240

13. Lockwood SM, Bannister K, Dickenson AH. An investigation into the noradrenergic and serotonergic contributions of diffuse noxious inhibitory controls in a monoiodoacetate model of osteoarthritis. J Neurophysiol. 2019;121(1):96-104. doi:10.1152/jn.00613.2018

14. Wen Y-R, Wang -C-C, Yeh G-C, et al. DNIC-mediated analgesia produced by a supramaximal electrical or a high-dose formalin conditioning stimulus: roles of opioid and alpha2-adrenergic receptors. J Biomed Sci. 2010;17(1):19. doi:10.1186/1423-0127-17-19

15. Itomi Y, Tsukimi Y, Kawamura T. Impaired diffuse noxious inhibitory controls in specific alternation of rhythm in temperature-stressed rats. Eur J Pharmacol. 2016;784:61-68. doi:10.1016/j.ejphar.2016.05.011

16. Yoneda S, Kasai E, Matsuo M, et al. Duloxetine ameliorates the impairment of diffuse noxious inhibitory control in rat models of peripheral neuropathic pain and knee osteoarthritis pain. Neurosci Lett. 2020;729:134990. doi:10.1016/j.neulet.2020.134990

17. Lapirot O, Melin C, Modolo A, et al. Tonic and phasic descending dopaminergic controls of nociceptive transmission in the medullary dorsal horn. Pain. 2011;152(8):1821-1831. doi:10.1016/j. pain.2011.03.030

18. François A, Low SA, Sypek EI, et al. A Brainstem-Spinal Cord Inhibitory Circuit for Mechanical Pain Modulation by GABA and Enkephalins. Neuron. 2017;93(4):822-839.e6. doi:10.1016/j. neuron.2017.01.008

19. Okada K, Oshima M, Kawakita K. Examination of the afferent fiber responsible for the suppression of jaw-opening reflex in heat, cold, and manual acupuncture stimulation in rats. Brain Res. 1996;740 (1-2):201-207. doi:10.1016/S0006-8993(96)00863-3

20. Normandin A, Luccarini P, Molat J-L, Gendron L, Dallel R. Spinal $\mu$ and $\delta$ opioids inhibit both thermal and mechanical pain in rats. $J$ Neurosci. 2013;33(28):11703-11714. doi:10.1523/JNEUROSCI.1631-13.2013

21. Todd AJ, Puskar Z, Spike RC, Hughes C, Watt C, Forrest L. Projection neurons in lamina I of rat spinal cord with the neurokinin 1 receptor are selectively innervated by substance p-containing afferents and respond to noxious stimulation. J Neurosci. 2002;22 (10):4103-4113. doi:10.1523/JNEUROSCI.22-10-04103.2002
22. Todd AJ. Anatomy of primary afferents and projection neurones in the rat spinal dorsal horn with particular emphasis on substance $\mathrm{P}$ and the neurokinin 1 receptor. Exp Physiol. 2002;87(2):245-249. doi:10.1113/eph8702351

23. Lapirot O, Chebbi R, Monconduit L, Artola A, Dallel R, Luccarini P. NK1 receptor-expressing spinoparabrachial neurons trigger diffuse noxious inhibitory controls through lateral parabrachial activation in the male rat. Pain. 2009;142(3):245-254. doi:10.1016/j. pain.2009.01.015

24. Patel R, Dickenson AH. A study of cortical and brainstem mechanisms of diffuse noxious inhibitory controls in anaesthetised normal and neuropathic rats. Eur $J$ Neurosci. 2020;51(4):952-962. doi:10.1111/ejn. 14576

25. Dickenson AH, Le Bars D. Morphine microinjections into periaqueductal grey matter of the rat: effects on dorsal horn neuronal responses to C-fibre activity and diffuse noxious inhibitory controls. Life Sci. 1983;33 Suppl 1(c):549-552. doi:10.1016/0024-3205(83) 90562-3

26. Phelps CE, Navratilova E, Dickenson AH, Porreca F, Bannister K. Kappa opioid signaling in the right central amygdala causes hind paw specific loss of diffuse noxious inhibitory controls in experimental neuropathic pain. Pain. 2019;160(7):1614-1621. doi:10.1097/j. pain.0000000000001553

27. Nation KM, De Felice M, Hernandez PI, et al. Lateralized kappa opioid receptor signaling from the amygdala central nucleus promotes stress-induced functional pain. Pain. 2018;159(5):919-928. doi:10.1097/j.pain.0000000000001167

28. Navratilova E, Nation K, Remeniuk B, et al. Selective modulation of tonic aversive qualities of neuropathic pain by morphine in the central nucleus of the amygdala requires endogenous opioid signaling in the anterior cingulate cortex. Pain. 2020;161(3):609-618. doi:10.1097/j.pain.0000000000001748

29. Dualé C, Molat JL, Dallel R. Morphine microinjected into the nucleus raphe magnus does not block the activity of spinal trigeminal nucleus oralis convergent neurons in the rat. Brain Res. 1998;803 (1-2):208-211. doi:10.1016/s0006-8993(98)00659-3

30. de Resende MA, Silva LFS, Sato K, Arendt-Nielsen L, Sluka KA. Blockade of opioid receptors in the medullary reticularis nucleus dorsalis, but not the rostral ventromedial medulla, prevents analgesia produced by diffuse noxious inhibitory control in rats with muscle inflammation. J Pain. 2011;12(6):687-697. doi:10.1016/j.jpain.2010.12.009

31. Le Bars D, Chitour D, Kraus E, Dickenson AH, Besson JM. Effect of naloxone upon diffuse noxious inhibitory controls (DNIC) in the rat. Brain Res. 1981;204(2):387-402. doi:10.1016/0006-8993(81)90597-7

32. Bing Z, Villanueva L, Le Bars D. Acupuncture and diffuse noxious inhibitory controls: naloxone-reversible depression of activities of trigeminal convergent neurons. Neuroscience. 1990;37(3):809-818. doi:10.1016/0306-4522(90)90110-P

33. Kraus E, Le Bars D, Besson JM. Behavioral confirmation of "diffuse noxious inhibitory controls" (DNIC) and evidence for a role of endogenous opiates. Brain Res. 1981;206(2):495-499. doi:10.1016/ 0006-8993(81)90554-0

34. Le Bars D, Chitour D, Kraus E, Clot AM, Dickenson AH, Besson JM. The effect of systemic morphine upon diffuse noxious inhibitory controls (DNIC) in the rat: evidence for a lifting of certain descending inhibitory controls of dorsal horn convergent neurones. Brain Res. 1981;215(1-2):257-274. doi:10.1016/0006-8993(81) 90506-0

35. Bouhassira D, Villanueva L, Le Bars D. Effects of systemic morphine on diffuse noxious inhibitory controls: role of the periaqueductal grey. Eur J Pharmacol. 1992;216(2):149-156. doi:10.1016/00142999(92)90355-8

36. Okada-Ogawa A, Porreca F, Meng ID. Sustained morphine-induced sensitization and loss of diffuse noxious inhibitory controls in dura-sensitive medullary dorsal horn neurons. J Neurosci. 2009;29 (50):15828-15835. doi:10.1523/JNEUROSCI.3623-09.2009 
37. Robbins A, Schmitt D, Winterson BJ, Meng ID. Chronic morphine increases Fos-positive neurons after concurrent cornea and tail stimulation. Headache. 2012;52(2):262-273. doi:10.1111/j.15264610.2011.01999.x

38. Bouhassira D, Villanueva L, Le Bars D. Intracerebroventricular morphine decreases descending inhibitions acting on lumbar dorsal horn neuronal activities related to pain in the rat. J Pharmacol Exp Ther. 1988;247(1):332-342.

39. Bouhassira D, Villanueva L, Le Bars D. Intracerebroventricular morphine restores the basic somesthetic activity of dorsal horn convergent neurones in the rat. Eur J Pharmacol. 1988;148(2):273-277. doi:10.1016/0014-2999(88)90574-2

40. Nation KM, Dodick DW, Navratilova E, Porreca F. Sustained exposure to acute migraine medications combined with repeated noxious stimulation dysregulates descending pain modulatory circuits: relevance to medication overuse headache. Cephalalgia. 2019;39 (5):617-625. doi:10.1177/0333102418804157
41. Lockwood SM, Dickenson AH. A combination pharmacotherapy of tapentadol and pregabalin to tackle centrally driven osteoarthritis pain. Eur J Pain. 2019;23(6):1185-1195. doi:10.1002/ejp.1386

42. Sanada T, Kohase H, Makino K, Umino M. Effects of alpha-adrenergic agonists on pain modulation in diffuse noxious inhibitory control. J Med Dent Sci. 2009;56(1):17-24.

43. Chitour D, Dickenson AH, Le Bars D. Pharmacological evidence for the involvement of serotonergic mechanisms in diffuse noxious inhibitory controls (DNIC). Brain Res. 1982;236(2):329-337. doi:10.1016/0006-8993(82)90718-1

44. Kraus E, Besson JM, Le Bars D. Behavioral model for diffuse noxious inhibitory controls (DNIC): potentiation by 5-hydroxytryptophan. Brain Res. 1982;231(2):461-465. doi:10.1016/0006-8993(82)90384-5

\section{Publish your work in this journal}

The Journal of Pain Research is an international, peer reviewed, open access, online journal that welcomes laboratory and clinical findings in the fields of pain research and the prevention and management of pain. Original research, reviews, symposium reports, hypothesis formation and commentaries are all considered for publication. The manuscript management system is completely online and includes a very quick and fair peer-review system, which is all easy to use. Visit http:// www.dovepress.com/testimonials.php to read real quotes from published authors. 